Makale Geliş | Received: 22.03.2019

Makale Kabul | Accepted: 09.04.2019

DOI: $10.18795 /$ gumusmaviatlas.543521

Mavi Atlas, 7(1)2019: 245-254. Araştırma Makalesi | Research Article

\author{
Yakup TOPAL \\ Dr. Öğr. Üyesi | Assist. Prof. Dr. \\ Gümüşhane Üniversitesi, Edebiyat Fakültesi, Türk Dili ve Edebiyatı Bölümü, Gümüşhane, TÜRKIYYE \\ Gumushane University, Faculty of Letters, Department of Turkish Language and Literature, Gumushane, TURKEY \\ yakuptopal@gumushane.edu.tr
}

\title{
Değerler Eğitimi ve On Kök Değer
}

\section{Öz}

Bir toplumun "muasır medeniyetler" seviyesini yakalayabilmesi; en başta üstün vasıflarla donanmış ahlâkî değerlere sahip gençler yetiştirmesiyle mümkündür. Bir ülkenin geleceğinin sağlam ve istenilen seviyede olabilmesinin temel şartı milli değerlerle yetiştirilmiş bireylere bağlıdır. Bu konuyla ilgili olarak Millî Eğitim Bakanlığı 2017 yılında müfredatta bazı değişiklikler yapılmasıyla ilgili basın açıklamasında "Değerler Eğitimi” konusu da gündeme getirmiş ve MEB değerler eğitiminde esas alınması gereken "on kök değer" tespit etmiştir. Bu çalışmanın temel amacı MEB tarafindan tespit edilen "on kök değer"in değerler eğitimi açısından genel bir değerlendirilmesini sağlamaktır. Çalışmanın amacı doğrultusunda yarı yapılandırılmış 4'lü likert ölçek şeklinde hazırlanan bir anket hazırlanmıştır. Bu anketle öğretmenlerin “On Kök Değer”e ilişkin görüşleri değerlendirilmiş, bu değerlerin yeterli olup olmadığ 1 , bu değerlerden başka manevî ve dinî değerlere yer verilip verilmemesiyle ilgili öğretmen görüşleri alınmıştır. 2018-2019 eğitim-öğretim yılında Trabzon ve Gümüşhane illerindeki farklı branşlardan 67 öğretmen üzerinde uygulanan bu araştırmada 2017 yılında uygulamaya konulan “on kök değer"in derslerde ne ölçüde öğrenilip öğrenilmediği konusunda öğretmen görüşlerini değerlendirmektedir. Araştırmaya katılan öğretmenler; vatanseverlik, sevgi, saygı, dostluk,yardımseverlik ve adalet değerlerinin öğrencilere yeterli seviyede öğretildiği, diğer değerlerin öğretilmesinde yeterli düzeye ulaşılamadığı doğrultusunda görüş belirtmişlerdir.

Anahtar Kelimeler: Eğitim, Değer, On Kök Değer, Değerler Eğitimi,.

\section{Values Education and Ten Root Value}

\begin{abstract}
It is possible for a society to catch "the contemporary civilization"; at first, to grow up the youngs having moral values, equipped with superior qualifications. The main condition of being strong and at wanted level of the future of a countrty is depended on the persons grown up with national values. The Ministry of Education brought on the agenda the subject of "Values Education" on a press birifing about making some changes in cirriculum in 2017 and MEB (Ministry of Education) detected "ten root values" which must be taken as basic principles. The main aim of this article is to have a general evaluation of detected "ten root values" in the view of "Values Education". A half configured 4-point likert scale has been prepared for the purpose of this study. With this survey, the view of the teachers about "Ten Root Values" has been evaluated, the teachers' opinions about whether these values are enough or not and if moral and religious values different from these values should be placed or not have been taken. In this study applied on 67 teachers from different branches, working at Trabzon and Gümüşhane in 2018-2019 education year, the teachers' opinions in what measure "ten root values", applied in 2017, has been able to learned or not at courses have been evaluated. The teachers joined in the survey have defined that the values of patriotism, love, respect, friendship, helpfulness and justice have been taught at wanted level, but other values have not been.
\end{abstract}

Keywords: Education, Value, Ten Root Value, Values Education 


\section{Giriş}

Değer; kullanıldığı bağlama, referans alınan değersayıma (paradigma) göre oldukça farklı anlamlara gelebilen, geniş kullanım alanına sahip bir kavramdır. 'Türkçede karşılık olma'yı dile getiren değmek kökünden türetilmiştir, bu anlamda bir şeye biçilen karşılık’tır, bundan ötürü de karşıladığı ihtiyaca göre değişen bir nitelik anlamını içerir." (Hançerlioğlu, 2005, s. 275). Değer, bir şeyin önemini belirlemeye yarayan soyut ölçü, bir şeyin değdiği karşılık, kıymet (TDK, 1998, s. 538), bireyin kendi yaşamında neyin doğru, neyin yanlış olduğu konusundaki geliştirdiği inançları, arzu edilen ve edilmeyen yargıları (Dilmaç, Deniz ve Deniz, 2009, s. 10), arzu edilen, arzu edilebilen şey, olaylarla ilgili insan tavrı, olgular ve nesneler hakkında ihtiyaç ve ideallere göre verilen yargı (Bolay, 1997, s. 93), tavır ve hareketin genel yöneticileri (Dönmezer, 1982, s. 253), bir şeyin arzu edilir veya edilemez olduğu hakkındaki inanç (Güngör, 2010, s. 27), bir şey veya kimsenin taşıdığg yüksek mânevî vasıf, meziyet, kıymetli nitelik (Ayverdi, 2006, s. 648), belli bir toplumda, neyin iyi, neyin kötü, doğru veya yanlış, arzu edilir veya edilmez olduğu konusundaki ortak görüşler, standartlar (Budak, 2005, s.195), Bir ölçüt olarak, olanla olması gereken ayrımını içerir ver her zaman olumlu ya da olumsuz bir şey olarak (Cevizci, 1999, s. 201) olarak tanımlanmaktadır.

Değerler, toplumdaki bireylerin korumaları veya göz ardı etmeleri neticesinde ya zamanla kaybolur veya nesilden nesile aktarılarak yıllarca devam ettirilebilir. Birçok toplum tarafindan kabul gören ve yıllarca sürdürülen genel (evrensel) değerler incelendiğinde ise karşımıza, liderlik, doğruluk, ahlak, adalet, sorumluluk ve yardımseverlik gibi bireyi ideal insan olma çizgisine yönlendiren değerler çıkmaktadır.

Kişiler, dâhil oldukları grup, toplum ve kültür değerlerini genellikle benimseyerek, bunları kendi muhakeme ve seçimlerinde birer ölçüt olarak kullanırlar (Dilmaç, 2009, s.29). Toplumlar, birçok yönden birbirlerinden farklılıklar göstermişler, ideal insan oluşturma yönündeki değerleri daima önemsemiş ve her dönem yaşatmaya çalışmışlardır.

Günümüz toplumlarında, bu tarz üstün değerlerin yaşatılması ve yeni nesillere aktarılması görevini üstlenen kurumlar arasında okullar da yer alır (Belet, 2008, s.2). Bilişsel hedeflerinin yanında vatansever olmak, saygılı olmak, dürüst olmak ve adil olmak gibi birçok duyuşsal hedefi olan okulların görevlerinden biri, okul programında açık olarak belirtilen veya belirtilmeyen değerleri öğretmek, öğrencileri belirlenen 
kurallar doğrultusunda disipline etmek, onların ahlaki gelişimlerine katkıda bulunmak ve karakterlerini olumlu yönde etkilemektir (Akbaş, 2008, s.9).

Türkçe ve Edebiyat dersi; öğrencilere doğru ve güzel okuyup yazmay1, dinlemeyi, konuşmayı ve dil bilgisi kurallarını uygulamayı öğretmenin yanı sıra; onlara millî, ahlakî, sosyal ve evrensel değerleri kazandırmayı amaçlar. Dersin bu amaçlarına ulaşabilmek için kullandığı ana malzeme ise ders kitapları ve bu kitaplarda verilen metinlerdir (Şen, 2008, s.764). Bu metinler; öğrencilere anadilini sevdirecek, kültürel ve tarihi değerlere karşı onların ilgilerini uyandıracak, bilişsel ve duyuşsal bakımdan onlara birçok beceri kazandıracak ve çeşitli mesajlar vererek onları eğitecek nitelikte olmalıdır. Kısacası, Türkçe ve edebiyat derslerinin iskeletini oluşturması, dersi ayakta tutan materyaller olması yönünden bu metinlerin önemi büyüktür (Solak, 2009, s.446).

2017 yılının Temmuz ayında Milli Eğitim Bakanlığı eğitim ve öğretim felsefesini belli oranda değiştirmiştir. "Millî Eğitim Bakanlığının değişen felsefesi doğrultusunda müfredatları geliştirme, yenileme ve güncelleme çalışmaları 2005 'te yeni bir rayda başlamış, 2015-2016 eğitim öğretim yılında tamamlanmıştır. 2016-2017 eğitim öğretim yılının başından bugüne ise farklı bir boyut kazanarak 51 müfredat ekseninde kapsamlı bir şekilde bir yenileme (güncelleme, gözden geçirme, ikmal ve değişiklik) çalışması yapılmıştır.’(MEB, Basın Açıklaması, s.3)

Yenilenen müfredatlarda esas alınan bazı ölçütler şunlardır:

"Yenilenen müfredatların sade ve anlaşılır olması ön planda tutulmuştur." "Öğrencilere kazandırılması hedeflenen yeterlilik ve beceriler belirlenirken derslerin tabiatı (disiplinin kendi özgül özellikleri) dikkate alınmıştır." "Yenilenen müfredatlar ile öğrencilere kazandırılması hedeflenen temel yeterlilik ve beceriler tüm disiplin alanları için ortak olarak verilmiştir." "Müfredatlarda disiplin alanlarına özgü yeterlilik ve becerilere yer verilmiştir." "Müfredatların yenilenmesi çalışmaları sırasında değerlerin öğrencilere aktarılmasında izlenen yöntemlere ve bu aktarımın etkililiğinin nasıl arttırılacağına ilişkin literatür taraması yapılmıştır." "Dersin bağlam ve kazanımlarından, konu anlatımından ve akışından kopuk olarak verilen değerler anlamlı ve kalıcı olmamaktadır." "Müfredatlar yenilenirken farklı kültür ve medeniyet havzalarının katkıları belirginleştirilmeye ve dengeli örneklemelerde bulunmaya çalışılmıştır." "Yenilenen müfredatlarda sadeleştirme ve içerik yoğunluğunun azaltılması ön planda tutulmuştur."

Talim ve Terbiye Kurulu Başkanlığı'nın 18 Temmuz 2017 tarihinde "Müfredatta Yenileme ve Değişiklik Çalışmalarımız Üzerine” başlığıyla yayınladığı bu bildirisinde 
"Değerler Eğitimi”’ne ilişkin “on kök değer”den bahsedilmiştir. Bu değerler: "adalet, dostluk, dürüstlük, öz denetim, sabır, saygı, sevgi, sorumluluk, vatanseverlik, yardımseverlik" olarak sunulmuştur.

Değerler, toplumu yapı taşı olan bireylere, nelerin önemli olduğunu, hangi durumlarda nasıl bir davranışın tercih edilmesi gerektiğini kavratmaya çalışan mana yüklü kavramlardır.

Eğitim kurumlarının hedefleri incelendiğinde; vatansever olma, yardımseverlik, sağlığına dikkat etme, fedakârlık, düzenli olma, adaletli olma, yaratıcı ve üretici olma, girişimci olma gibi birçok değer içerdiği görülmektedir. Eğitimin önemli amaçlarından biri de belli değerlerin öneminin öğrencilere kavratılması ve yaşatılmasıdır. Bu yolda eğitim kurumları ve öğretmenler öğrencilere rehberlik ederler. $\mathrm{Bu}$ durum bir bakıma duyuşsal eğitime girmektedir. Elbette ki okullar olduğu müddetçe duyuşsal eğitim de olacaktır. Çünkü okullar bilginin bilgisizlikten, sosyal düzenin düzensizlikten daha değerli ve önemli olduğunu öğretirler. Kerschensteiner (1954) ise insanların oluşturduğu bütün ekiplerin değerler geliştirmesi gerektiğini anlatır. Karakter eğitimiyle ilgili birçok çalışması bulunan Lickona (1992) ise değer eğitimi için demokratik bir toplumun başarısıyla ilgili temel olduğu görüşünü savunur.

Klâsik eğitim anlayışımızda "edeb" eğitiminin çokça üzerinde durulmakta ve bu ahlâkî değerlerin kavratılması anlamına gelmektedir. Yunus Emre’ni ifadesiyle

"Girdim ilim meclisine, eyledim kıldım talep / dediler ilim geride, illa edep illa edep." Buradan da milletçe tarihî serüvenimizde edeb kelimesinin terbiye ile beraber kullanıldığını görüyoruz. Eğitim tarihimizde "Terbiye" ifadesi "eğitim" kavramını karşılayan bir kelimedir.

Millî Eğitim Bakanlığının "adalet, dostluk, dürüstlük, öz denetim, sabır, sayg1, sevgi, sorumluluk, vatanseverlik, yardımseverlik" maddelerinde özetlediği “on kök değer" "namaz kılma, dua etme, Allah’tan korkma" gibi manevî değerlerine yer verilmemiştir. Bin yıldan beri Müslümanlık değerleriyle yoğrulan bir milletin dinle ilgili değerlerine "on kök değer" içinde yer verilmemesi bir eksikliktir. Müslümanlıkla yoğrulan Türk insanını tahlil ettiğimiz zaman bazı manevî yükümlülüklerini yerine getiremese bile bunu bir eksiklik olarak kabul etmekte ve birçoğu ilerleyen yaşlarda manevî değerleri yaşamaya daha büyük önem vermektedir. Yani toplumda bazı manevî değerler yaşanmasa da doğruluğu ve gerekliliği kabul edilmektedir. Bu durum değerlerin daha fazla olması gerektiği kanaati doğurmaktadır. 


\section{Araştırmanın Amacı}

$\mathrm{Bu}$ araştırmanın amacı, 2017 yılında uygulamaya konulan “on kök değer"in derslerde ne ölçüde öğrenilip öğrenilmediği konusunda öğretmen görüşlerini incelemektedir.

2.1. Problem Cümlesi: Yapılan bu çalışmada aşağıdaki sorulara cevap aranmıştır.

1. Öğretmenler, derslerde yapılan çalışmalarda on kök değerle (adalet, dostluk, dürüstlük, öz denetim, sabır, saygı, sevgi, sorumluluk, vatanseverlik, yardımseverlik) ilgili yapılan okuma, çalışma ve etkinlikleri yeterli bulmakta midirlar?

2. On kök değer (adalet, dostluk, dürüstlük, öz denetim, sabır, sayg1, sevgi, sorumluluk, vatanseverlik, yardımseverlik) değerler eğitimi için yeterli midir?

3. Değerler eğitimi kapsamında manevî ve dinî değerlere daha çok yer verilmeli midir?

\section{2. Sayıltular}

Araştırmaya katılan bütün öğretmenler veri toplama aracında yer alan soruları doğru cevaplamışlardır.

\section{3. Sinırlılıklar}

Araştırma, 2018-2019 Trabzon ve Gümüşhane illerinde görev yapan ve yarı yapılandırılmış anketimize katılmayı kabul eden farklı branşlardan ilkokul, ortaokul ve lise öğretmenleriyle sınırlıdır.

\section{Yöntem}

\section{1. Araştırmanın Yöntemi}

Bu araştırmada betimleme yöntemi kullanılmıştır. "Durum nedir? Neredeyiz?" gibi sorulara, mevcut zaman dilimi içinde olduğu düşünülen verilere dayanılarak cevap bulmak istenir. Bir "Survey Yöntemi” olarak bilinen betimleme yöntemi, grupla ilgili, genişliğine (Cross-Sectional) bir çalışmadır. $\mathrm{Bu}$ tür araştırmalar, çok sayıda kişi üzerinde ve belirli bir zaman dilimi içinde yapılmaktadır.(Kaptan, 1998: 59)

\section{2. Araștırmanın Örneklemi}


Gümüşhane ve Trabzon'da görev yapan öğretmenler araştırmanın evrenini oluşturmaktadır.

\section{3. Araştırmanın Çalışma Grubu}

$\mathrm{Bu}$ araştırmanın çalışma grubunu Gümüşhane ve Trabzon'da görev yapan öğretmenler 67 ilkokul, orta okul ve lise öğretmeni oluşturmaktadır.

\subsection{Verilerin Toplanması}

Survey yöntemiyle yapılan bu araştırmada veri toplama aracı olarak dört dereceli bir Likert ölçek kullanılmıştır. 67 ilkokul, orta okul ve lise öğretmeni öğretmeniyle yüz yüze görüşülmüş konu hakkında bilgilendirilmiş ve bu öğretmenlerin yarı yapılandırılmış ankete katılmaları sağlanmıştır. Araştırmaya başlamadan önce de konu hakkında benzer araştırmalar incelenmiştir.

\subsection{Verilerin Analizi}

Anket sorucu elde edilen veriler Excel programında değerlendirilmiş; madde bazında frekans(n-sayı) ve yüzde(\%) kullanılmıştır.

\subsection{Bulgular ve Yorum}

Tablo 1: Öğretmenlerin “On Kök Değer”e Karş1 Görüşlerine İlişkin Bulgular

\begin{tabular}{|c|c|c|c|c|c|c|c|c|}
\hline & \multicolumn{2}{|c|}{$\begin{array}{l}\text { Tamamen } \\
\text { Kat1lyyoru } \\
\mathrm{m}\end{array}$} & \multicolumn{2}{|c|}{ Kat1liyorum } & \multicolumn{2}{|c|}{$\begin{array}{l}\text { Kararsiz1 } \\
\mathrm{m}\end{array}$} & \multicolumn{2}{|c|}{ Kat1lmiyorum } \\
\hline & $\mathrm{n}$ & $\mathrm{f}$ & $\mathrm{n}$ & $\mathrm{F}$ & $\mathrm{n}$ & $\mathrm{f}$ & $\mathrm{n}$ & f \\
\hline $\begin{array}{l}\text { 1.Derslerde öğrencilere "adalet" } \\
\text { değerini kavratmaya yönelik yeterli } \\
\text { sayıda okuma çalışmaları, uygulama ve } \\
\text { etkinlikler yapılmaktadır. }\end{array}$ & 22 & $32,8 \%$ & 25 & $37,3 \%$ & 5 & $7,5 \%$ & 15 & $22,4 \%$ \\
\hline $\begin{array}{l}\text { 2.Derslerde öğrencilere "dostluk" } \\
\text { değerini kavratmaya yönelik yeterli } \\
\text { sayıda okuma çalışmaları, uygulama ve } \\
\text { etkinlikler yapılmaktadır. }\end{array}$ & 28 & $41,8 \%$ & 21 & $31,3 \%$ & 6 & $9,0 \%$ & 12 & $17,9 \%$ \\
\hline $\begin{array}{l}\text { 3.Derslerde öğrencilere "dürüstlük" } \\
\text { değerini kavratmaya yönelik yeterli } \\
\text { sayıda okuma çalışmaları, uygulama ve } \\
\text { etkinlikler yapılmaktadır. }\end{array}$ & 18 & $26,9 \%$ & 15 & $22,4 \%$ & 16 & $23,9 \%$ & 18 & $26,9 \%$ \\
\hline $\begin{array}{l}\text { 4. Derslerde öğrencilere "öz denetim" } \\
\text { değerini kavratmaya yönelik yeterli } \\
\text { sayıda okuma çalışmaları, uygulama ve } \\
\text { etkinlikler yapılmaktadır. }\end{array}$ & 13 & $19,4 \%$ & 12 & $17,9 \%$ & 27 & $40,3 \%$ & 15 & $22,4 \%$ \\
\hline
\end{tabular}




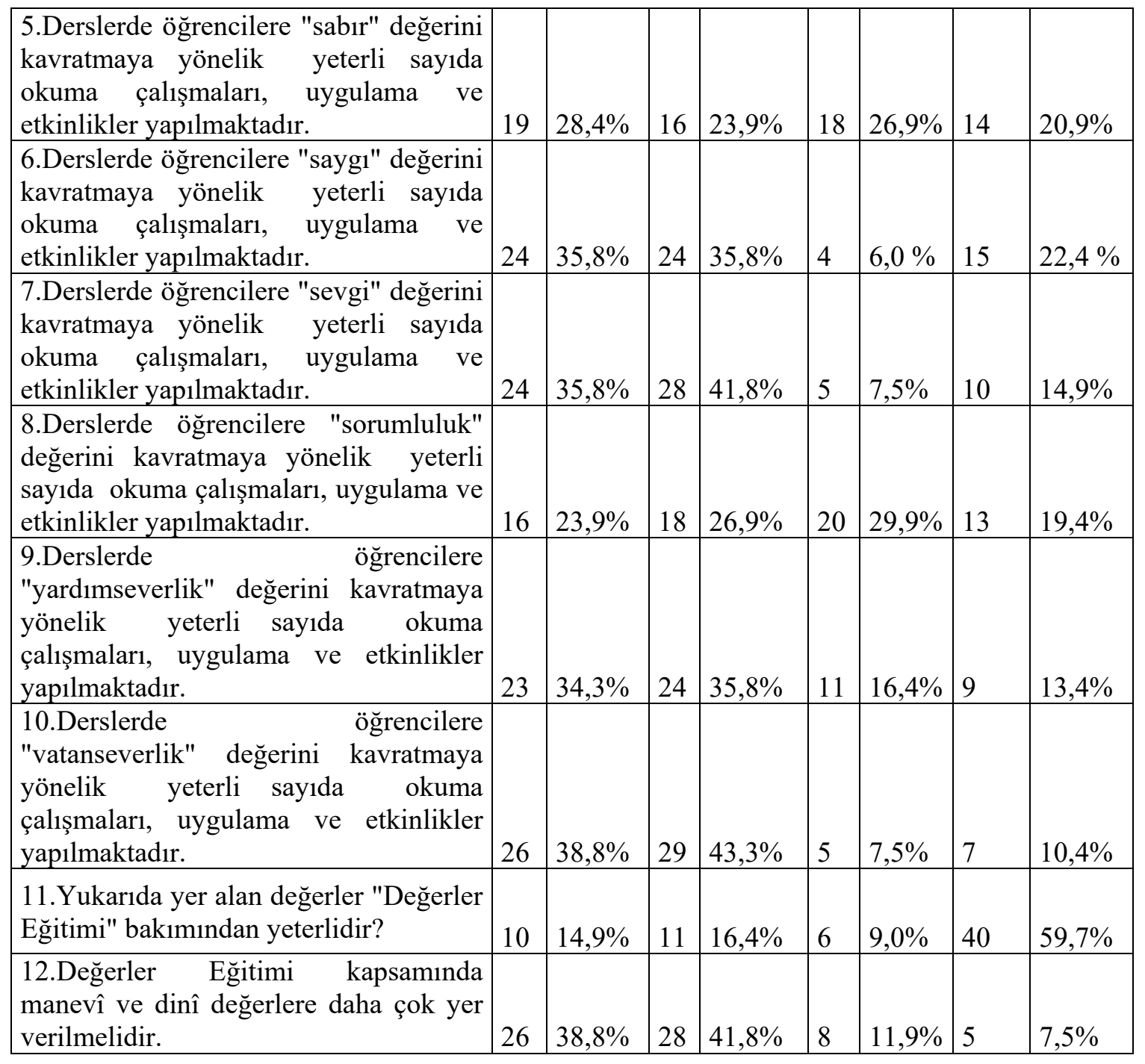

Tabloya göre derslerde en çok işlenen değerlerin sırasıyla "vatanseverlik (kat1lyorum ve tamamen kat1liyorum 82,1 ort.), "sevgi" (kat1lyyorum ve tamamen kat1liyorum 77,6 ort.), "dostluk" (kat1liyorum ve tamamen kat1liyorum 73,1 ort.), "sayg1" (katıliyorum ve tamamen katıliyorum 71,6 ort.), "yardımseverlik" ve "adalet" (katıliyorum ve tamamen kat1liyorum 70,1 ort.), "sabır" (kat1liyorum ve tamamen kat1liyorum 52,2 ort.), "sorumluluk" (kat1liyorum ve tamamen kat1liyorum 50,7 ort.) olarak sıralanmaktadır. Öğretmenler, "dürüstlük” (katıllyorum ve tamamen katılıyorum 49,3 ort.), ve "öz denetim" (katıliyorum ve tamamen kat1lyorum 37,3 ort.), değerlerinin ise yüzde ellinin altında olarak derslerde ver verildiği yönünde görüş belirtmişlerdir.

11. soruya verilen cevaba göre ise öğretmenlerin yaklaşık yüzde $\% 60$ 'ının on kök değer olarak ifade edilen maddelerin değerler eğitimi için yeterli olmadı̆̆ 
görüşündedir. 12. soruya verilen cevaba göre ise öğretmenlerin yaklaşık yüzde 80’i dinî ve manevî değerlerin derslerde daha çok yer alması gerektiğini düşündüğü anlaşılmaktadır.

\section{Tartışma ve Sonuç}

İnsanların güzel davranışlara yönelmesi toplumun güzelleşmesi, ideal bir ahlâkî yapıya ulaşması için en önemli unsurdur. Ahlak ve karakter eğitimiyle ilgili birçok çalışmada "Okullar hangi özellikte ve nitelikte insanlar yetiştirmelidir? Okulların temel hedefleri neler olmalıdır?" soruları sorulmuş ve bu soruların cevabı olarak; okulların verdiğgi eğitimi alan bir öğrencinin; onur sahibi, adil, cesur, görev bilinci yüksek, vatansever, yardımsever, ahlâkî karakteri yüksek bir birey olması istenmiştir.

Toplumun iyiliğine ve güzelliğe yönelik davranışlar kazandırma gibi temel bir amaçla hareket eden eğitim kurumlarının görevlerinden biri de değer eğitimidir. Eski ilköğretim programlarında genel hedefler içinde yer verilmiş olan değerlere, yeni ilköğretim programlarının bazılarında programın değerleri başlığı altında yer verilmiş, bazılarında ise eski eğitim programlarda olduğu gibi programın genel hedefleri kısmında yer almaya başlanmıştır.

Değerler ve değer eğitimi; ahlak eğitimi, irade eğitimi, karakter eğitimi, vatandaşlık eğitimi gibi isimlerle öğretim programlarında bulunmaktadır. Millî Eğitim Bakanlığının "adalet, dostluk, öz denetim, dürüstlük, sabır, sorumluluk, vatanseverlik, yardımseverlik, saygı, sevgi," maddelerinde özetlediği "on kök değer" "namaz kılma, dua etme, Allah'tan korkma" gibi manevî değerlerine yer verilmemiştir. Bin yıldan beri Müslümanlık değerleriyle yoğrulan bir milletin dinle ilgili değerlerine "on kök değer" içinde yer verilmemesi bir eksikliktir. Müslümanlıkla yoğrulan Türk insanını tahlil ettiğimiz zaman bazı manevî yükümlülüklerini yerine getiremese bile bunu bir eksiklik olarak kabul etmekte ve birçoğu ilerleyen yaşlarda manevî değerleri yaşamaya daha büyük önem vermektedir. Yani toplumda bazı manevî değerler yaşanmasa da doğruluğu ve gerekliliği kabul edilmektedir. Bu durum değerlerin daha fazla olması gerektiği kanaati doğurmaktadır.

Çalışmamızda kullandığımız ankete göre uygulamamıza katılan öğretmenlerin yaklaşık yüzde \%60'ının on kök değer olarak ifade edilen kavramların değerler eğitimi için yeterli olmadığı görüşündedir. Yine çalışmamıza katılmayı kabul eden öğretmenlerin yaklaşık yüzde 80'i dinî ve manevî değerlerin derslerde daha çok yer alması gerektiğini düşündüğü anlaşılmaktadır. 
Çalışmaya katılan öğretmenler, söz konusu on değerin 6 tanesinin(vatanseverlik, sevgi, saygı, dostluk, yardımseverlik ve adalet) derslerde öğrencilere büyük oranda öğrencilere verildiğini düşünmekte ancak sabır, sorumluluk, dürüstlük değerlerinin kısmen öğrencilere verildiği, özellikle "öz denetim” değerinin öğrencilere verilmesinde ciddi anlamda eksiklik olduğu yönünde görüş bildirmişlerdir.

Onur sahibi, adil, cesur, görev bilinci yüksek, vatansever, yardımsever, ahlâkî karakteri yüksek bir bireylerin yetiştirilmesi ve ülkemizin bu özelliklere sahip insanlara teslim edilmesi geleceğimiz adına en önemli meselemizdir. Eğitim sistemimizin bu özelliklere sahip bireyler yetiştirmesi de değerler eğitiminin doğru ve etkili şekilde yürütülmesine bağlıdır. Bu bakımdan değerler eğitimiyle ilgili çalışmalar büyük önem taşımaktadır.

\section{Kaynaklar}

BELET, Dilek ve Handan DEVECİ (2008). Türkçe Ders Kitaplarının Değerler Açısından İncelenmesi, VII. Ulusal Sınıf Öğretmenliği Sempozyumu, 2-4 Mayıs 2008, Çanakkale.

BOLAY, S. H. (1997). Felsefi Doktrinler ve Terimler Sözlüğü, Ankara: Akçăg Basım Yayın.

CEVİCí, A. (1999). Paradigma Felsefe Sözlüğü, İstanbul: Paradigma Yayınları.

DİLMAÇ, B., ERTEKİN, E., YAZICI, E., (2009). "Değer Tercihleri ve Öğrenme Stilleri Arasındaki İlişkinin İncelenmesi”, Değerler Ĕ̆itimi Dergisi, 7(17): $27-47$.

DİLMAÇ, B., Deniz, M. ve M.E. Deniz, (2009). “Üniversite Öğrencilerinin Öz Anlayışları ile Değer Tercihlerinin İncelenmesi”, Değerler Eğitimi Dergisi, 7(18): 9-24.

DÖNMEZER, S. (1982). Sosyoloji, Ankara: Savaş Yayınları.

GÜNGÖR, E. (2010). Değerler Psikolojisi Üzerinde Araştırmalar. İstanbul: Ötüken Neşriyat.

HANÇERLIOĞLU, O. (2005). Felsefe Ansiklopedisi Kavramlar ve Akımlar, Cilt 1, İstanbul: Remzi Kitabevi.

KAPTAN, S. (1998). Bilimsel Araştırma ve İstatistik Teknikleri, Ankara: Tekışık Web Ofset Tesisleri. 
KERSCHENSTEINER, G. (1954). Karakter Kavramı ve Karakter Terbiyesi, çev. H. Fikret Kanad, Ankara: Örnek Matbaası.

LİCKONA, T. (1992). Educating for Character (How our schools can teach respect and resposibility). New York: Bantam Books

SOLAK, M. ve Derya YAYLI, (2009) "İlköğretim İkinci Kademe Türkçe Kitaplarının Türler Açısından İncelenmesi”, Uluslararası Sosyal Araştırmalar Dergisi, 2(9): 444-453.

ŞEN, Ü. (2008). “Altıncı Sınıf Ders Kitaplarındaki Metinlerin İlettiği Değerler Açısından İncelenmesi”, Uluslararası Sosyal Araştırmalar Dergisi, 1(5): 763-779.

Türk Dil Kurumu, (1998). Türkçe Sözlük, Cilt 1 (9. Bask1), Ankara: Türk Dil Kurumu Yayınları.

https://ttkb.meb.gov.tr/meb_iys_dosyalar/2017_07/18160003_basin_aciklamasiprogram.pdf(MEB, Basın Açıklaması, 2017 Temmuz). Er. Tar. 13 Şubat 2019 